Amazonía Peruana, Volumen XVI, No 32, 2019; p.p 61-72

\title{
PACTOS ENTRE PUEBLOS INDÍGENAS Y \\ EL ESTAdO EN LA AMAZONÍA PERUANA \\ REPUBLICANA
}

\author{
Frederica Barclay Rey de Castro
}

\section{Resumen}

Este artículo retoma el caso del pacto colonial entre el Estado peruano y los indígenas chasuta, puesto en evidencia por un levantamiento acontecido en 1893, para proponer la utilidad heurística de la noción de pactos entre el Estado y colectividades étnicas. Se pone en relieve la dimensión de las percepciones en que los pactos se fundan, y se aplica al caso más contemporáneo del pueblo awajún a partir del análisis de la percepción en que el pacto se funda y de las condiciones de la ruptura de este acuerdo a raíz del acuerdo de paz entre Perú y Ecuador en 1998.

\section{Summary}

This article takes up the case of the colonial pact between the Peruvian State and the indigenous Chasuta people, made evident by an uprising in 1893, to propose the heuristic usefulness of the notion of agreements between the State and ethnic communities. It highlights the dimension of the perceptions on which the agreements were founded, and applies it to the more contemporary case of the Awajun people, based on an analysis of perceptions on which it was founded and the conditions of the breakdown of this agreement as a result of the peace settlement between Peru and Ecuador in 1998.

Palabras claves: Pactos-Amazonía-sujetos étnicos-pueblos indígenas-Perú 


\section{Introducción}

Acudí a la noción de pacto colonial al estudiar un levantamiento ocurrido en la región amazónica peruana prestándola de otros contextos temporales y geográficos para señalar la continuidad de arreglos pre-republicanos en la región amazónica donde se había implantado un orden colonial-misional (Barclay 2001).

En este artículo exploro la utilidad de la noción de pactos remitiéndome tanto al caso de Chasuta conocido a partir de una revuelta ocurrida en 1893, como a la discusión generada en torno a pactos coloniales en su contexto andino, para elaborar en torno a su naturaleza enfatizando las dimensiones de la percepción y estrategias colectivas de cara a este tipo de acuerdos, que destaca Ana María Soux (2006) y proyectarlos al análisis de un caso contemporáneo.

\section{Pactos coloniales en la Amazonía}

El levantamiento de Chasuta, en 1893, entonces perteneciente al departamento de Loreto, en la cuenca del río Huallaga, fue provocado por el intento de las autoridades republicanas de desconocer arreglos establecidos anteriormente con los chasuta adscritos al centro poblado de origen misional del mismo nombre (Barclay 2001). Estos acuerdos databan de la época colonial. La población indígena perteneciente a la circunscripción de Chasuta había adquirido el estatus de catequizada y libre, como varias otras de las llamadas misiones alta y baja, por haber aceptado el ordenamiento misional en el marco del cual, a cambio de determinadas obligaciones, quedaba exenta de otras más gravosas (Scazzocchio 1981: 107; Santos Granero y Barclay 2002).

Las obligaciones de los chasutas pactadas por las autoridades competían a tareas que los indígenas debían cumplir de cara a la misión y el régimen colonial. Estas incluían: sostener a los misioneros (mediante diversos servicios y tasas), respetar el calendario festivo religioso, actuar como bogas para el transporte de carga y pasajeros bajo acuerdo con sus autoridades propias, y mantener libre de palizadas el estrecho pasaje del Pongo de Aguirre. Este último punto era fundamental para la comunicación por el Huallaga y para la extracción y circulación de la sal que constituía un elemento de gran importancia en el circuito misional.

A cambio, los chasutas quedaban exonerados de otras tareas impuestas por el régimen colonial y sus autoridades a los pueblos conquistados. Quedaban también exonerados de obligaciones forzosas con particulares y gozaban del derecho de elegir a sus propias autoridades étnicas para intermediar en la relación con las misiones y el Estado.

De acuerdo con documentación del año 1893, procedente del Archivo General de la Nación (Fondo Ministerio del Interior, Serie Prefecturas)], el hecho que desató el levantamiento fue la pretensión de imponerles la obligación de trabajar en el 
desbroce y construcción de un camino a Tarapoto que excedía los términos de este pacto inicial. Esta documentación resultó muy rica tanto para conocer la percepción étnica de aquel pacto, como para apreciar palpablemente el proceso de disolución de los arreglos previos gestados en el marco del ordenamiento misional colonial.

Como señalé anteriormente (Barclay 2001), aunque no existe evidencia de un pacto formalizado por escrito entre el régimen colonial y los chasutas, la reacción colectiva, cuya motivación fue explicitada por los líderes indígenas y recogida por las autoridades civiles republicanas que acudieron a atender el levantamiento, se demostraba que el ordenamiento colonial había continuado en pie, aunque estaba siendo progresivamente desmantelado por el desarrollo de la nueva economía extractiva y la evolución de las relaciones de poder en la cuenca del Huallaga.

El levantamiento ponía en evidencia que la población local chasuta estuvo dispuesta a defender un arreglo socio-político que reflejaba el hecho colonial de su subordinación política al poder misional-colonial, el cual les imponía cargas laborales y limitaba su autonomía política y de movimiento a cambio de mantener ciertas prerrogativas. Es relevante señalar que estos arreglos se habían originado en un contexto en el que la tutela misional, por más detestable que resultara, marcaba la diferencia entre una situación caracterizada por la completa arbitrariedad en el abuso del empleo de la mano de obra, y otra donde las obligaciones se encontraban acotadas a un conjunto de tareas claramente delimitadas.

Forzados a aceptar este arreglo frente a la indefensión originada en las epidemias masivas, las «correrías» para la captura de mano de obra y una serie de abusos por parte de las autoridades civiles, emerge, al menos del contexto de la disolución de este régimen, la evidencia de la agencia política indígena y no solo su sometimiento. Surge también, en este contexto, la evidencia que la continuidad de los arreglos políticos implicó un nivel de negociación basado en una apreciación colectiva de sus opciones.

El caso de los chasutas, quienes defendieron lo que entendían había sido un acuerdo firme entre ellos y el Estado colonial y su aparato misional, no es el único de esta naturaleza en la región amazónica. Los habitantes indígenas de otros conglomerados misional-coloniales, como los jeberos, defendieron los arreglos misionales frente a las autoridades coloniales. Respecto de los arreglos coloniales con los jeberos, hoy autodenominados shiwilu, señala el jesuita de Figueroa (1986: 188): "están por particular merced reserbados [sic] de mita y tributo, dedicados solamente a las cosas de guerra y servicio de los padres en lo tocante a descubrimientos y reducciones".

Tras la expulsión de los jesuitas de los territorios hispánicos en América, por Cédula Real de 1767, los jeberos alegaron -y los hicieron por escrito- que ellos tenían derechos pactados que les garantizaban poder retirarse periódicamente a sus "tambos", siempre y cuando regresaran al poblado para las fiestas y para cumplir con 
los turnos de trabajo acordados (Porras 1987). Ello no impidió que, considerándolos importantes aliados locales de la corona, el gobernador Francisco de Requena los enviara a la frontera del Brasil donde se rebelaron y desde donde la mayoría logró regresar. Apelando a un pacto más que centenario y a su condición de indios libres, en 1808 los jeberos encabezaron una revuelta contra el nuevo Gobernador de Maynas cuando éste pretendió impedir que se celebrara la fiesta del primer día del año en que se elegían a sus autoridades indígenas, las que organizaban los turnos de trabajo y velaban para impedir ocurrieran «excesos» (Julou citado Surrallés y García Hierro 2011: 19). Después de todo, de acuerdo con la tradición oral de los shiwilu, habían sido ellos quienes invitaron a los españoles a asentarse en sus tierras (Surrallés y García Hierro 2011: 31).

\section{Pactos coloniales en los Andes}

En la historiografía andina la noción de pacto colonial ha sido empleada de forma relativamente extensa para caracterizar arreglos políticos relacionales, de origen colonial, entre la corona y la población indígena, derivados de una situación de vasallaje, es decir, asentados en un contexto de dominación. La literatura coloca como contexto de los pactos coloniales la existencia de las llamadas dos repúblicas, o la existencia de estamentos étnicos. La noción de pacto colonial interviene como factor que explica el hecho colonial de la dominación no sustentado exclusivamente en el uso de la violencia (Bridikhina 2015).

Tristan Platt en El Estado boliviano y ayllu andino (1982), su clásico estudio sobre los ayllus del norte de Potosí, hizo notar que aquellos habían reivindicado a inicios del período republicano la existencia de arreglos coloniales para defenderse del intento de imposición de nuevas obligaciones. Denominándolos también "pactos de reciprocidad", Platt mostró cómo estos pactos operaban, no en términos genéricos, sino entre el Estado y una determinada colectividad étnica, y sustanció la racionalidad de los ayllus al defender un arreglo fundado en la subyugación política que venía de antaño.

Con el tiempo, el planteamiento de Platt -que otros investigadores han profundizado-, ha recibido diversas críticas, que van desde el señalamiento que se trata de "una elaboración académica que traduce la visión o la 'ilusión' de los autores" (Heraclio Bonilla citado en Mendieta, 2005: 132) hasta la acusación de que la propia noción de pacto colonial no hace sino legitimar las relaciones de poder (Larson 1992). Otros autores han negado la continuidad de los arreglos coloniales en los países andinos al inicio de la república, pero como argumenta Mendieta (2005: 132) es posible que esta continuidad se haya visto condicionada por factores que van desde las evoluciones socio-políticas regionales hasta las características sociológicas de las colectividades que reclamaron su continuidad cuando esta fue desafiada por el poder republicano. A este punto se requiere aclarar que empleo el término de colectividad y la expresión colectividad étnica para resaltar la que, en todos los casos, los indígenas involucrados en los pactos entienden, perciben y declaran que estos 
acuerdos se establecen con ellos y no con otros indígenas y, por lo tanto, reclaman la especificidad de su situación y no una situación genérica de sujeción al Estado.

Bien que pudo haber existido diferencias sub-regionales en la región andina, algunas observaciones de Soux (2006; 2008) son relevantes para situar la trascendencia de los pactos. Para el caso boliviano Soux (2008: 19) aborda los pactos desde la perspectiva de percepciones de las colectividades indígenas involucradas, señalando al mismo tiempo que se trató de "estrategias políticas de adaptación al complejo proceso de dominación". De ahí su énfasis en recuperar la agencia de los indígenas como actores políticos frente al hecho de la dominación.

Es posible apreciar, entonces, en contextos bastante diversos en términos temporales y étnico-geográficos, que las relaciones políticas entre colectividades étnicas y el Estado han sido traducidas eventualmente al idioma de estos pactos de origen colonial para reflejar determinados arreglos diferenciados, los que aunque sustentados en el hecho de la dominación- han sido invocados y defendidos colectivamente cuando bajo determinadas circunstancias el estado colonial o republicano, ha pretendido imponer nuevos arreglos sociopolíticos o alterar los términos de la relación de subordinación. .

El hecho de que estos pactos hayan sido estudiados a propósito de su invocación tardía, al verlos amenazados por un nuevo ordenamiento político, no permite establecer de qué manera fueron originalmente formalizados o explicitados. Sin embargo, no queda duda de que, por algún tiempo, éstos fueron también reconocidos por las autoridades, civiles o religiosas, y no solo por los propios indígenas.

En cualquier caso, pareciera ser que los pactos se construyeron sobre la base de un orden colonial instituido y dentro de sus márgenes, pero negociados específicamente con colectividades que, en virtud de determinadas circunstancias, pudieron establecer condiciones que, a la postre, podemos reconocer como relativamente ventajosas respecto de otras colectividades.

Esta aproximación a las relaciones coloniales y post-coloniales entre los indígenas y el Estado colonial y republicano permite visualizar a unas colectividades o segmentos de ellas percibiendo e interpretando contextos, definiendo estrategias de cara a una situación dada y deseable, y leyendo las relaciones de poder.

\section{Un pacto no colonial: el caso awajún}

Me propongo ahora sugerir y demostrar que la noción de pacto puede ser empleada ventajosamente para comprender la percepción indígena de su agencia y situación relacional con el Estado en contextos más contemporáneos, e inclusive sin mediar un antecedente colonial, empleando para ello el caso de los awajún, antes llamados aguaruna. 
Había sugerido ya la idea de la percepción e invocación de un pacto de los awajún con el Estado peruano, a través de los militares, en un informe elaborado para ODECOFROC, (2009) que alude a un período en el que se instaló entre los awajún la percepción de que el pacto establecido décadas antes, con ellos, ya no valía más.

El pueblo awajún ha sido históricamente la antípoda de los indios catequizados o cristianos, como lo fueron los chasutas y jeberos. Su discurso histórico enfatiza su voluntad de mantener su libertad y recupera la memoria de los múltiples intentos por conquistarlos y someterlos y su denodada defensa de su autonomía, incluyendo su exitosa resistencia a la conquista u ocupación inca y su participación en las tempranas rebeliones jíbaro en el siglo XVI.

Un tema de debate en 1983, cuando fui por primera vez al Alto Marañón, a territorio awajún, era el recuento de las consideraciones en torno a las decisiones que habían tomado colectivamente cuatro o cinco décadas atrás. Surgían en estas conversaciones las referencias a los intensos y prolongados debates que tuvieron lugar acerca de la respuesta que correspondía dar a la creciente presencia de militares y la implantación de colonizadores en su territorio, aprovechando la construcción de carreteras, una situación que se configuraba nueva, a pesar de que años antes, se habían establecido allí comerciantes caucheros y algunos misioneros evangélicos. Una constante que emergía en los relatos era la caracterización de tres marcadas posturas: por un lado, la posición de determinados líderes que llamaban a tomar las lanzas (nagki juta) para expulsar otra vez a los que amenazaban su autonomía; de otro, la de quienes llamaban a aceptar la nueva realidad de una presencia poderosa y demográficamente inagotable que traía consigo el acceso a mercaderías; $\mathrm{y}$, por último, la de quienes llamaban a establecer un pacto a partir de un análisis estratégico. Había quienes para ello hacían mención a los relatos históricos que señalaban que los awajún muchas veces habían buscado aliados para vencer situaciones que los amenazaban.

Fue la tercera posición la que fue ganando terreno a partir de la identificación del contexto y del rol de los militares en este territorio de frontera. El territorio awajún hacía parte de una amplia franja de territorio en disputa entre Perú y Ecuador que en 1941 llevó a una confrontación armada, luego de la cual se firmó el Protocolo de Río de Janeiro al año siguiente. Como precisamente en territorio awajún la línea de frontera no pudo delimitarse debido a que el reconocimiento del terreno mostró que la configuración hidrográfica no era la que se había supuesto en esa zona, el protocolo fue pocos años después cuestionado por el Ecuador. Por esa razón el territorio awajún al norte del Marañón continuó siendo motivo de un diferendo internacional que llevó a que el Perú conservara en esa zona numerosos puestos y campamentos militares a fin de asumir el control territorial.

De esta alianza resultó lo que los awajún percibieron -hasta muy recientementecomo un pacto firme con los militares y, a través de ellos, con la República peruana. Cabe señalar que este pacto resultaba tanto más relevante cuanto que ninguna 
norma hasta entonces reconocía derechos, de ningún tipo y menos a la seguridad de la tierra y bosques, a los indígenas amazónicos.

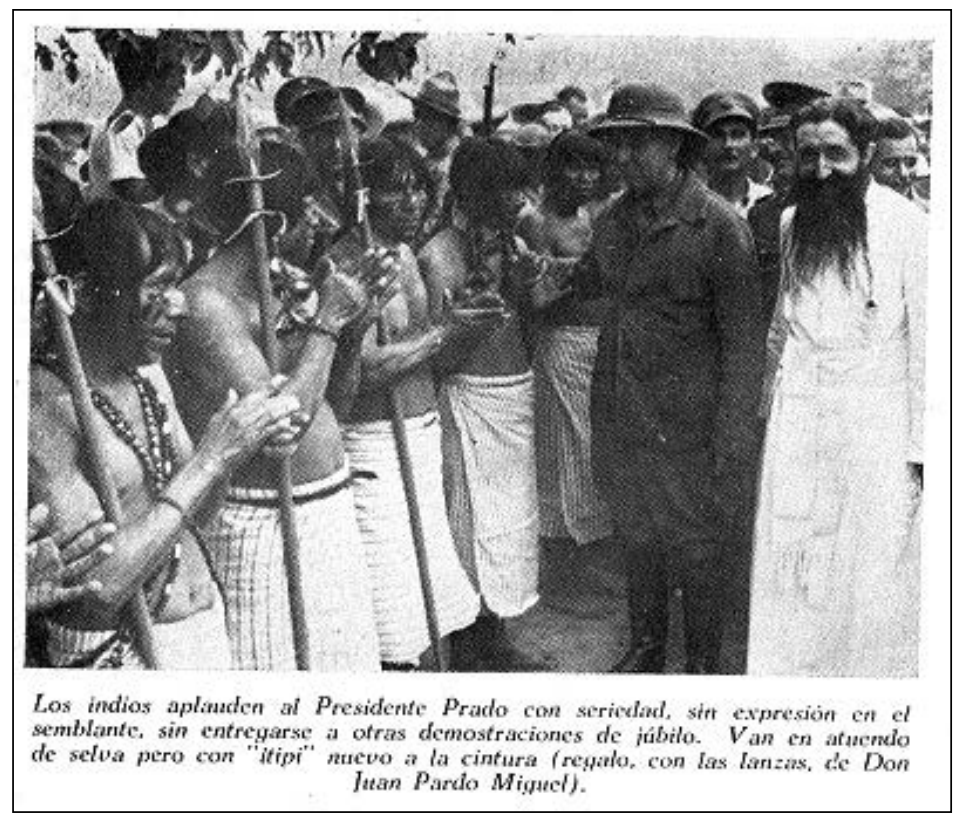

Fuente: Luz sobre el Marañón. Gonzalo Palacios de Borao, SJ. 1945. p. 52 Lima: Compañia de Jesús.

El punto de partida/convergencia no era una situación de subordinación o vasallaje, como los pactos coloniales al decir de Soux y de Platt, aunque el pacto implicó aceptar la presencia militar. Desde la perspectiva awajún se trataba de un pacto entre iguales por el cual los awajún terminaban la resistencia armada (dejaban sus lanzas) a cambio de que los militares, representantes del poder foráneo, los reconocieran como un pueblo autónomo, conservando, como dicen los awajún, su dignidad, y se garantizara sus territorios.

Ello no se consiguió sin conflictos. Ahí queda como evidencia el relato que figura en La Casa Verde de Vargas Llosa acerca de cómo un muun llamado Jum fue vejado por las autoridades civiles luego de que éste y su gente expulsaran de Urakusa a los militares porque habían molestado a las mujeres de su comunidad. Desde la perspectiva de algunos de esos líderes, como este pacto resultaba imperfecto o insuficiente, los awajún aceptaron también la presencia del Instituto Lingüístico de Verano (ILV) que traía la oportunidad de aprender a leer y escribir en castellano, a fin de tratar con esos "otros" en mejores términos, y sin tener que recurrir nuevamente a sus lanzas. Un poco más tarde, en paralelo a la vigencia del pacto con los militares, los awajún, junto con los wampis, a través del Consejo Aguaruna y Huambisa, fundado en la década de 1970 -cuando ya al menos se había 
promulgado la Ley de Comunidades Nativas (1974)- se empeñaron en conquistar sus derechos ciudadanos.

Por imperfecto que fuera este acuerdo, los awajún continuaron considerando que mantenían un pacto con los militares peruanos. Y, puede decirse en este caso, que el Ejército peruano, que era responsable de guardar la frontera no delimitada, pareció concebir la relación como un pacto que también establecía obligaciones al Estado peruano a través de su aparato militar.

Con el tiempo, este pacto llevó a que la mayor parte de los soldados de las guarniciones militares «de frontera» pasaran a ser reclutas awajún de modo que, tras un enfrentamiento militar con tropas ecuatorianas ocurrido en 1981, el Ejército reconoció la significativa contribución militar indígena. Si bien en los alejados puestos militares de frontera los abusos fueron un hecho frecuente, en el marco del arreglo sociopolítico local, esta inclusión parece haber sido leída como un elemento adicional del «pacto» entre iguales.

Un nuevo enfrentamiento entre el Perú y Ecuador, más grave aún, tuvo lugar en 1995 y reafirmó el compromiso awajún con las fuerzas armadas peruanas. Cuando éste culminó, al llamado de los países garantes del Protocolo de 1942, se inició la negociación de un nuevo acuerdo de paz. Pero, este nuevo contexto, vino a traer cambios sustanciales en los términos de la relación entre los awajún del Alto Marañón y el Estado peruano.

En agosto de 1997, cuando el acuerdo de paz se encontraba en negociación, Evaristo Nugkuag, importante líder indígena, que había sido presidente del Consejo Aguaruna y Huambisa y que, en esa función, había llevado adelante numerosas negociaciones con el Ejército y con el gobierno peruano, me señaló que él y otros líderes veían con preocupación el acuerdo de paz . Como buen estratega, Nugkuag anticipaba que, una vez que los awajún ya no fuesen necesarios para asegurar la presencia militar peruana en la región, los términos de sus relaciones habrían de cambiar drásticamente, intuyendo que perderían las ventajas relativas que habían tenido hasta entonces.

No era solo que anticipaban que, al término del conflicto binacional, llegaran las carreteras que hasta entonces solo bordeaban su territorio por ser zona de frontera, lo que les había permitido lograr que un bloque importante de su territorio fuera delimitado y titulado. Ello, naturalmente, preludiaba la llegada masiva de colonos que disputarían sus territorios y recursos. También anticipaban con claridad que el Ejército y el Estado peruano dejarían de tenerles la relativa consideración que les habían ofrecido.

Como muestra de esa consideración, todavía en la víspera de la firma del Acuerdo de Paz entre Perú y Ecuador, la Cancillería convocó al Consejo Aguaruna y Huambisa y sus líderes más connotados a una reunión en Lima para exponerles la postura desde la que se estaba negociando ese acuerdo binacional (ODECOFROC 
2009: 24). Esto constituye una indicación de que, hasta entonces, los militares y Lima acreditaban la existencia de dicho pacto.

Sin embargo, una vez firmado el acuerdo, ocurrió lo que Nugkuag temía: en este ámbito, el Estado peruano se autonomizó y empezó a actuar al margen de la relación con los awajún. Por lo pronto, en 1999, el Estado declaró unilateralmente como zona reservada una gran área denominada Santiago-Comainas, que comprometía territorios de los pueblos awajún y wampis por la administración peruana. Los pueblos awajún y wampis lograron que se excluyeran de la zona reservada las áreas comunales y las que desde la década anterior venían solicitando se les titulara. En ese marco propusieron al Estado ceder más de 150,00 hectáreas en tierras indígenas ubicadas en las cabeceras del río Cenepa para establecer un Parque Nacional que contribuyera a sellar la frontera y al mismo tiempo asegurar la conservación de un área donde especuladores estaban interesados en la explotación de oro.

Pero, evidenciando el resquebrajamiento del orden previo y la ruptura del pacto con los militares, luego que en 2004 se había acordado la creación del Parque Nacional Cordillera del Cóndor - Ichigkat Muja, y se había elaborado de común acuerdo su Plan Maestro, en el 2007, el Estado peruano decidió, con aprobación de las fuerzas armadas, recortar el área prevista para permitir el establecimiento de actividades mineras.

El informe en minoría de la comisión creada para investigar los sucesos de Bagua acontecidos en 2009, tras el violento sofocamiento policial de una protesta en la que participaban cerca de cinco mil manifestantes, atribuye al recorte del Parque Nacional para autorizar la minería aurífera, y a la percepción local de una traición por parte del Estado peruano, la masiva participación awajún en el bloqueo de la carretera (Valverde y Gómez Calleja 2010: 44-50). El informe hizo notar también que, si bien en las movilizaciones y protestas del 2008 y 2009 participaron todos los pueblos amazónicos como reacción a la presentación de numerosos proyectos de ley, en el caso del Marañón, hubo un activo involucramiento de toda la población indígena de las cuencas y comunidades.

Para los awajún, estas medidas fueron percibidas como la decisión del gobierno de debilitar las garantías y seguridad de sus derechos territoriales y el recorte del Parque Nacional establecido en su territorio, evidencia que el Estado peruano había dejado atrás ese pacto que, con tanto esfuerzo, habían procurado mantener. Fue en ese marco que la ruptura del pacto fue interpretada como un intento del Estado, otrora su aliado, de acabar con los awajún (Santos Granero y Barclay 2010).

\section{Discusión}

Este artículo propone reconocer la equivalencia entre los pactos históricos establecidos o así percibidos, entre el Estado colonial y colectividades étnicas, y el pacto establecido entre los awajún y el Ejército peruano a mediados del siglo XX, para 
proponer su utilidad como recurso heurístico. El uso de la noción de pacto enfatiza como lo sugiere Soux (2008: 19), la perspectiva y percepción de las colectividades indígenas para caracterizar arreglos de naturaleza política en contextos en los que el Estado colonial o republicano reclama la soberanía y el derecho de ejercer su poder, convirtiendo y tratando a estas colectividades como sujetos étnicos, para usar la expresión de Andrés Guerrero (Guerrero 1997).

La noción de pacto no pretende negar el hecho de la dominación en el contexto colonial, ni de la pérdida de autonomía en el contexto más contemporáneo analizado aquí, sino que resalta, como ha enfatizado Soux (2006), la agencia indígena en la percepción de las opciones, la anticipación de las consecuencias de los cambios en los términos de relacionamiento y el manejo de estrategias negociadas.

Entre estas estrategias se cuenta las decisiones colectivas de apelar al reclamo de un pacto vulnerado para exigir que los términos del arreglo de relacionamiento no sean modificados por el Estado en la medida que estos cambios afectan el posicionamiento de la colectividad.

Si bien los pactos de origen colonial en el contexto amazónico, establecidos entre la corona por intermedio de los misioneros y quienes fueron categorizados como categorizados y libres, tienen una especificidad que deriva de la existencia de un orden estamental, entonces, que ya no está vigente, considero que mucho avanzamos si comprendemos que la noción de pactos, cambiantes y renegociados, contribuye a entender la manera en que los pueblos indígenas amazónicos han concebido la manera en que se deben establecer las relaciones entre ellos y el Estado.

Surge entonces la pregunta de si un contexto en el que no existe ya un orden estamental ni poblaciones al margen del ordenamiento estatal debe permitirse la continuidad de pactos entre indígenas y el Estado ¿La progresiva extensión de la ciudadanía se contradice con esta opción?

Las iniciativas recientes de algunos pueblos de reclamarse sujetos colectivos en su condición de originarios frente al Estado peruano y, al mismo tiempo, de reconocerse como ciudadanos peruanos, remite de alguna manera a una noción de pacto que requiere un marco constitucional distinto, que demanda, en palabras de Guerrero (2007), de ciudadanías étnicas y acuerdos no genéricos que respeten la personalidad política de cada pueblo, basado en políticas de derechos colectivos para el ejercicio de su autonomía en un marco plurinacional, posibilidad a la que el Estado se resiste por lo que implica en términos de consentimiento. Así, se ha preferido mantener la fórmula comunidades nativas como sujetos-administrados.

Pienso que vale la pena que emplee la hipótesis de la existencia y/o percepción de pactos específicos entre colectividades y quienes detentan la autoridad, a sus ojos, para explorar históricamente y en lo contemporáneo los términos en que se perciben y construyen las relaciones entre los pueblos indígenas amazónicos y el Estado. 


\section{Bibliografía}

Barclay, Frederica

2001 "Cambios y continuidades en el pacto colonial en la amazonía. El caso de los indios Chasutas del Huallaga medio a finales del siglo XIX". En: Boletín del Instituto Francés de Estudios Andinos, vol. 30: no 2: 187-210.

Bridikhina, Evgenia

2015 "De lo colonial en los tomos de Bolivia, su historia". En: Tinkazos, vol.18 no.37 La Paz: julio 2015. http:/ / www.scielo.org.bo/scielo.php?script=sci_ arttext\&pid=S1990-74512015000100007 (mayo 2017).

Figueroa, Francisco, De Acuña, Cristobal y otros

1986 "Ynforme de las Misiones de el Marañon, Gran Pará o Río de las Amazonas". Informes de Jesuitas en el Amazonas 1660-1684. [1661]. Serie Monumenta Amazonica. Iquitos: CETA/IIAP: pp 143-309.

Larson, Brook

1992 "Explotación y economía moral en los Andes del sur: hacia una reconsideración crítica" En: Historia Crítica, 6 (1992). Bogotá: 75-97. 1992. https:/ / revistas.uniandes.edu.co/doi/abs/10.7440/histcrit6.1992.05 (mayo 2017).

Mendieta, Pilar

2005 "En defensa del pacto tributario. Los indígenas bolivianos frente al proyecto liberal: S. XIX". En: Revista Andina, Vol. 41, no.2: 231-154.

\section{ODECOFROC}

2009 Crónica de un engaño Los intentos de enajenación del territorio fronterizo Awajún en la Cordillera del Cóndor a favor de la minería. Informe IWGIA nº 5. Lima.

Platt, Tristan

1982 Estado boliviano y ayllu andino: tierra y tributo en el norte de Postosí. Lima: IEP.

Porras, María Elena

1987 Gobernación y Obispado de Mainas siglos XVII y XVII. Quito: Abya Yala/ THEIS.

Santos Granero, Fernando y Barclay, Frederica

2002 La frontera domesticada. Historia económica y social de Loreto, 1851-2000. Lima: Fondo Editorial de la Pontificia Universidad Católica del Perú. 
Santos Granero, Fernando y Barclay, Frederica

2010 "Bultos, selladores y gringos alados: percepciones indígenas de la violencia capitalista en la Amazonía peruana". En: Anthropologica, AÑO XXVIII, $\mathrm{N}^{\circ} 28$, Suplemento 1, pp. 21-52.

Scazzocchio, Françoise

1981 "La conquête des Motilones du Huallaga Central aux XVIIe et XVIII siècles". En: Boletín del Instituto Francés de Estudios Andinos, vol 10, nº 3-4: 99-111.

Soux, María Luisa

2006 "El mito de la igualdad ciudadana y la dominación postcolonial. Los derechos indígenas en la Bolivia del siglo XIX". En: Carrera Damas, E. et al. (Comp.), Mitos políticos en las sociedades andinas. Orígenes, invenciones y ficciones. Caracas: Equinoccio, Université de Marne la Vallée, IFEA, pp 343-362.

Soux, María Luisa

2008 "Tributo, constitución y renegociación del pacto colonial. El caso altoperuano durante el proceso de la independencia (1808-1826)". En: Relaciones, 115: 19-48.

Surrallés, Alex y García Hierro, Pedro

2011 Aportes de la sustentación del derecho al Territorio integral del Pueblo Shiwilu del Distrito de Jeberos. Documento elaborado con la Federación de Comunidades Nativas de Jeberos. Borrador para validar. (inédito).

Valverde, Jesús Manacés y Gómez Calleja, Carmen

2010 Informe en minoría de la Comisión Especial para Investigar y Analizar los Sucesos de Bagua. Lima. 